\title{
Impact of smoking on the outcome of anterior cervical arthrodesis with interbody or strut-grafting.
}

\author{
Alan Hilibrand \\ Rothman Institute, Thomas Jefferson University; University Hospitals Spine Institute, Department of \\ Orthopaedic Surgery, Case W. Reserve Univ. Sch. of Med. \\ Mark A. Fye \\ University Hospitals Spine Institute, Department of Orthopaedic Surgery, Case W. Reserve Univ. Sch. of \\ Med. \\ Sanford E. Emery \\ Mark A. Fye, University Hospitals Spine Institute, Department of Orthopaedic Surgery, Case W. Reserve \\ Univ. Sch. of Med. \\ Mark A. Palumbo

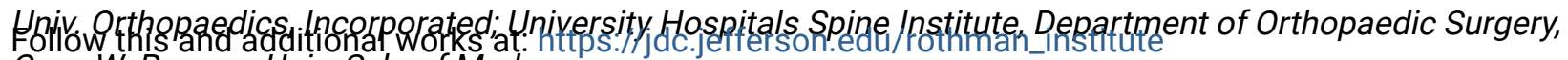 \\ Case W. Reserve Univ. Sch. of Med.
Part of the Orthopedics Commons \\ Henfy H, Bohlman, how access.to this docyment benefits, vou
}

Üniv. Sch. of Med.

\section{Recommended Citation}

Hilibrand, Alan; Fye, Mark A.; Emery, Sanford E.; Palumbo, Mark A.; and Bohlman, Henry H., "Impact of smoking on the outcome of anterior cervical arthrodesis with interbody or strutgrafting." (2001). Rothman Institute Faculty Papers. Paper 9.

https://jdc.jefferson.edu/rothman_institute/9

This Article is brought to you for free and open access by the Jefferson Digital Commons. The Jefferson Digital Commons is a service of Thomas Jefferson University's Center for Teaching and Learning (CTL). The Commons is a showcase for Jefferson books and journals, peer-reviewed scholarly publications, unique historical collections from the University archives, and teaching tools. The Jefferson Digital Commons allows researchers and interested readers anywhere in the world to learn about and keep up to date with Jefferson scholarship. This article has been accepted for inclusion in Rothman Institute Faculty Papers by an authorized administrator of the Jefferson Digital Commons. For more information, please contact: JeffersonDigitalCommons@jefferson.edu. 


\title{
IMPACT OF SMOKING ON THE OUTCOME OF ANTERIOR Cervical Arthrodesis With INTERBODY OR STRUT-GRAFTING
}

\author{
By Alan S. Hilibrand, MD, Mark A. Fye, MD, SANFORd E. EMery, MD, \\ Mark A. Palumbo, MD, and Henry H. Bohlman, MD \\ Investigation performed at the University Hospitals Spine Institute and the Department of Orthopaedic Surgery, \\ Case Western Reserve University School of Medicine, Cleveland, Ohio
}

\begin{abstract}
Background: An increased rate of pseudarthrosis has been documented following posterolateral lumbar spine grafting in patients who smoke. This same relationship has been assumed for anterior cervical interbody grafting, but to our knowledge it has never been proven. This study compared the long-term radiographic and clinical results of smokers and nonsmokers who had undergone arthrodesis with autogenous bone graft following multilevel anterior cervical decompression for the treatment of cervical radiculopathy or myelopathy, or both.

Methods: One hundred and ninety patients were followed clinically and radiographically for at least two years (range, two to fifteen years). Fifty-nine of the patients had corpectomy with strut-grafting, and 131 patients had multiple discectomies and interbody grafting. Fifty-five of the 190 patients had a history of active cigarette-smoking; fifteen of the fifty-five had corpectomy with strut-grafting, and forty had multilevel discectomies and interbody grafting. Internal fixation was not used in any patient. The reconstruction techniques and postoperative bracing regimen were similar between smokers and nonsmokers. Osseous union was judged on dynamic lateral radiographs made at least two years following surgery, and clinical outcomes were judged on the basis of pain level, medication usage, and daily activity level.

Results: Of the forty smokers who had undergone multilevel interbody grafting, twenty had a solid fusion at all levels, whereas sixty-nine of the ninety-one nonsmokers had solid fusion at all levels ( $p<0.02$; chi-square test). This difference was especially pronounced among patients who had had a two-level interbody grafting procedure $(p<$ 0.002 ; chi-square test). With the numbers available, there was no difference in the rate of fusion between smokers (fourteen of fifteen) and nonsmokers (forty-one of forty-four) who had undergone corpectomy and strut-grafting, as $93 \%$ of both groups had a solid union. In addition, clinical outcomes were significantly worse among smokers when compared with nonsmokers ( $p<0.03$; rank-sum analysis).

Conclusions: Smoking had a significant negative impact on healing and clinical recovery after multilevel anterior cervical decompression and fusion with autogenous interbody graft for radiculopathy or myelopathy. Since smoking had no apparent effect upon the healing of autogenous iliac-crest or fibular strut grafts, subtotal corpectomy and autogenous strut-grafting should be considered when a multilevel anterior cervical decompression and fusion is performed in patients who are unable or unwilling to stop smoking prior to surgical treatment.
\end{abstract}

$\mathrm{T}$ he adverse effects of smoking on the cardiovascular, respiratory, endocrine, and immune systems have been well documented, and the medical costs to society have recently been assessed ${ }^{1,2}$. Smoking has also been found to have major effects on the musculoskeletal system and is considered a risk factor for the development of osteoporosis and senile fractures.

A video supplement to this article is available from the Video Journal of Orthopaedics. A video clip is available at the JBJS web site, www.jbjs.org. The Video Journal of Orthopaedics can be contacted at (805) 962-3410, web site: www.vjortho.com.
Several investigations have shown that the results of lumbar spine surgery are also adversely affected by cigarette-smoking, with lower rates of fusion, poorer clinical outcomes, and higher rates of postoperative infection in smokers $^{4-11}$. Initially, it was postulated that the lower rate of consolidation of posterolateral lumbar spinal grafts among smokers was due to a lower oxygen-carrying capacity of the bloodstream ${ }^{4}$. However, it was recently demonstrated in a rabbit model that nicotine itself has a direct negative impact on bone-graft healing ${ }^{12,13}$.

Although several clinical studies have demonstrated the 
The Journal of Bone \& JOINT SURGERY • JBJS.ORG VOLUME 83-A · NUMBER 5 - MAY 2001
IMPACT OF SMOKING ON THE OUTCOME OF ANTERIOR CERVICAL ARTHRODESIS WITH INTERBODY OR STRUT-GRAFTING

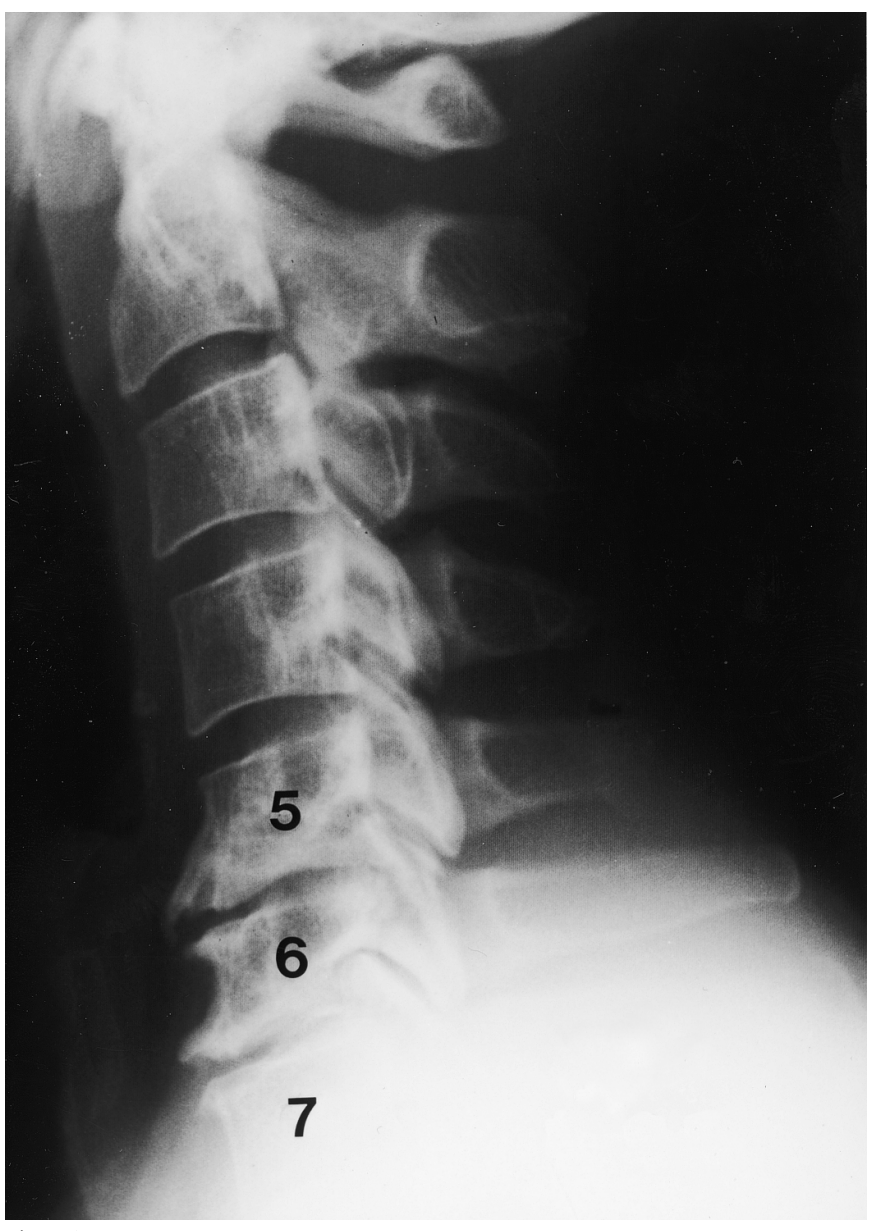

Fig. 1-A

Figs. 1-A and 1-B A forty-seven-year-old man with cervical spondylotic radiculopathy affecting the sixth and seventh cervical nerve roots and a history of cigarette-smoking. Fig. 1-A Preoperative lateral radiograph of the cervical spine, demonstrating spondylosis at the fifth and sixth and the sixth and seventh cervical levels.

negative impact of smoking on the consolidation of posterolateral lumbar grafts, the effects of smoking on the healing of anterior cervical interbody grafts are less well defined. Bishop et al. ${ }^{14}$ found that smoking hindered healing of allogenic but not autogenous bone grafts. Bohlman et al. ${ }^{15}$ and An et al. ${ }^{16}$ suggested that there was a trend toward more nonunions among smokers treated with arthrodesis with autogenous interbody grafts than among nonsmokers so treated, but neither showed a significant difference. Also, none of these studies examined the effect of a history of smoking on clinical outcomes.

The present study was designed to assess the impact of smoking on the success of multilevel arthrodesis following extensive anterior cervical decompressive procedures. We also compared the clinical outcomes of smokers and nonsmokers treated with this procedure. Finally, we sought to identify operative strategies that might be applied to the smoking population in order to improve treatment outcomes.

\section{Materials and Methods}

From 1973 through 1992, the senior one of us (H.H.B.) perF formed 252 multilevel anterior cervical decompression and fusion procedures with autogenous bone-grafting. Of the 252 patients, 190 were evaluated clinically and radiographically at least two years following operative treatment and they comprised the study group. The procedures were performed on patients with cervical radiculopathy or myelopathy due to degenerative spondylosis or a herniated nucleus pulposus. Preoperatively, all patients had clinical and radiographic evidence of multilevel cervical spondylosis with compression of nerve roots or the spinal cord, or both. The duration of clinical and radiographic follow-up averaged sixty-eight months, with a range of twenty-four to 183 months.

\section{Operative Procedures}

One hundred and ninety patients with mild spondylosis or disc herniations causing nerve-root or cord compression at

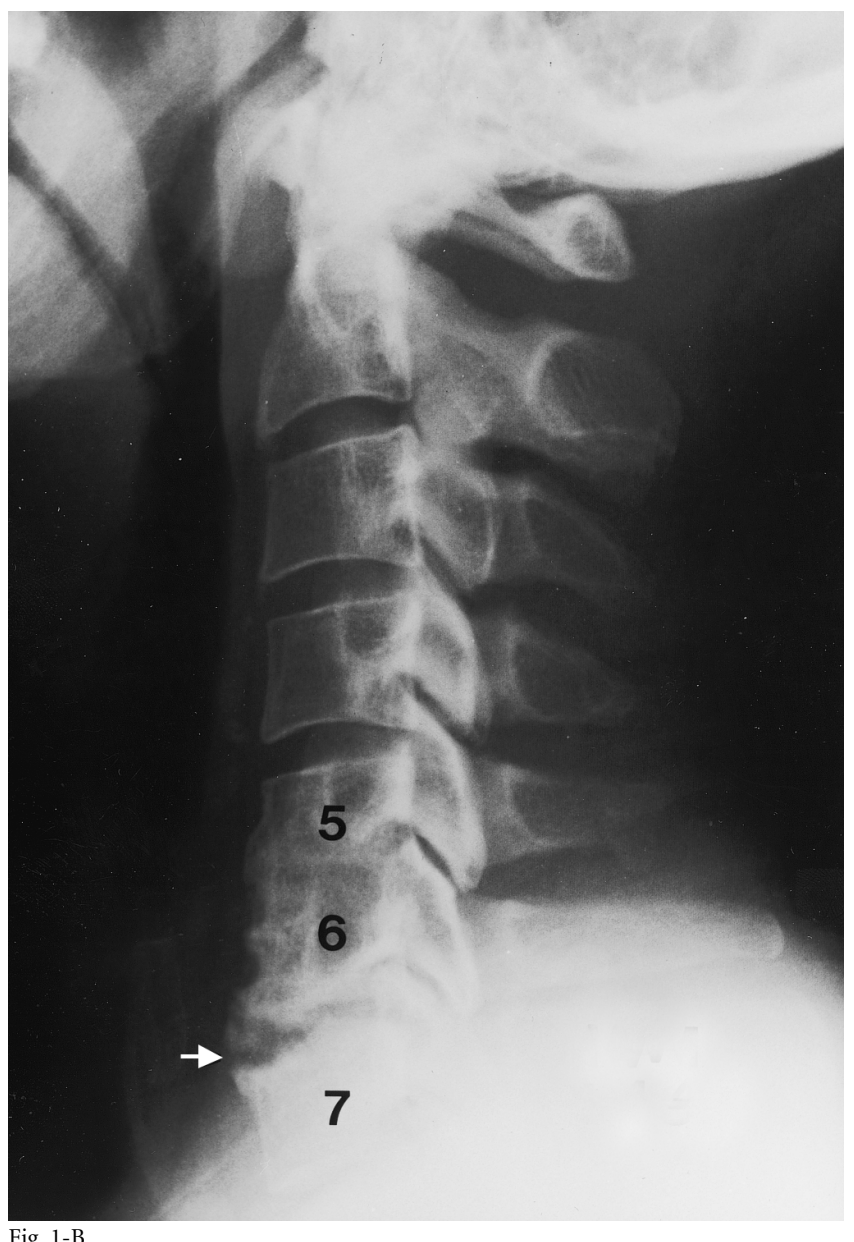

Lateral radiograph made thirty-nine months after interbody arthrodesis between the fifth and sixth and the sixth and seventh cervical vertebrae, demonstrating healing and consolidation between the fifth and sixth vertebrae and nonunion with graft resorption (arrow) between the sixth and seventh cervical vertebrae. 
TABLE I Success of Arthrodesis Among Nonsmokers and Smokers According to Type of Procedure

\begin{tabular}{|c|c|c|c|}
\hline & $\begin{array}{l}\text { No. of Patients } \\
\text { with Solid Fusion }\end{array}$ & $\begin{array}{l}\text { Total No. } \\
\text { of Patients }\end{array}$ & $\begin{array}{c}\text { Percentage } \\
\text { of Patients } \\
\text { with Solid Fusion }\end{array}$ \\
\hline \multicolumn{4}{|l|}{ All patients } \\
\hline Total & 144 & 190 & $76 \%$ \\
\hline Nonsmokers & 110 & 135 & $81 \%$ \\
\hline \multirow[t]{2}{*}{ Smokers } & 34 & 55 & $62 \%$ \\
\hline & & & $\mathrm{p}<0.02 *$ \\
\hline \multicolumn{4}{|c|}{ Multilevel discectomy and interbody grafting } \\
\hline Nonsmokers & 69 & 91 & $76 \%$ \\
\hline \multirow[t]{2}{*}{ Smokers } & 20 & 40 & $50 \%$ \\
\hline & & & $\mathrm{p}<0.02 *$ \\
\hline \multicolumn{4}{|c|}{ Two-level procedures } \\
\hline Nonsmokers & 53 & 66 & $80 \%$ \\
\hline \multirow[t]{2}{*}{ Smokers } & 15 & 32 & $47 \%$ \\
\hline & & & $\mathrm{p}<0.002 *$ \\
\hline \multicolumn{4}{|c|}{ Three-level procedures } \\
\hline Nonsmokers & 16 & 25 & $64 \%$ \\
\hline Smokers & 5 & 8 & $63 \%$ \\
\hline \multicolumn{4}{|c|}{ Subtotal corpectomy and strut-grafting } \\
\hline Nonsmokers & 41 & 44 & $93 \%$ \\
\hline Smokers & 14 & 15 & $93 \%$ \\
\hline
\end{tabular}

*The $\mathrm{p}$ values represent the difference between the nonsmokers and the smokers.

the level of the intervertebral disc had an anterior cervical discectomy and arthrodesis performed as described by Robinson and Smith ${ }^{17}$. Ninety-eight of the patients had a two-level discectomy and thirty-three had a three-level discectomy with interbody iliac-crest grafting. A review of data in the office chart and in the hospital anesthesia records revealed that thirty-two of the ninety-eight patients who underwent a twolevel procedure and eight of the thirty-three patients who underwent a three-level procedure had a history of active tobacco use (cigarette-smoking). Fifty-nine patients with neural element compression posterior to the vertebral body itself had single or multilevel subtotal corpectomy and strutgrafting performed as described by Emery et al. ${ }^{18}$. Of the fiftynine patients, sixteen had a corpectomy with iliac-crest or fibular strut-grafting at one level; twenty-one, at two levels; twenty, at three levels; and two, at four levels. Four of the one-level, five of the two-level, and six of the three-level procedures were done in patients with a history of smoking. Autogenous iliac-crest graft was used in one and two-level corpectomies, and autogenous fibular graft was used in two, three, and four-level corpectomies.

No internal fixation was used in this study. Postoperatively, 174 patients were treated with a two-poster cervical orthosis or a rigid collar, nine patients were treated with a halo, and four patients were treated with a soft collar. The form of postoperative immobilization was not recorded for three of the patients. The smokers and nonsmokers were treated with similar methods of postoperative immobilization.

\section{Follow-up Evaluation}

Following the operation, patients were seen at regular intervals by one of us. The severity and location of any symptoms, use of analgesic medications, functional status, work status, and results of a complete neurological examination were documented. Flexion and extension lateral radiographs of the cervical spine were made at each visit to determine the status of the fusion. A solid fusion was defined as $\leq 1 \mathrm{~mm}$ of change, between flexion and extension radiographs, in the interspinous distance across a grafted segment and by continuous osseous trabeculation without any intervertebral lucency at the site of the arthrodesis. Clinical outcomes at the most recent followup visit were assessed with use of a modification of the functional analysis of Robinson et al. ${ }^{19}$. In this system, the primary determinant of outcome is the patient's subjective rating of the pain level. Secondary and tertiary determinants of outcome are requirements for pain medication and work status or activity level, respectively.

\section{Data Analysis}

The records for all patients were independently reviewed, and the pertinent data were recorded in a Microsoft Access database (Redmond, Washington). The success of the arthrodesis was compared between smokers and nonsmokers with use of chi-square analysis. Clinical outcomes, scored independently with the functional criteria described by Robinson et al..$^{19}$, were compared between groups with rank-sum analysis. Significance for each test was established at $\mathrm{p}<0.05$. 
THE JOURNAL OF BONE \& JOINT SURGERY · JBJS.ORG VOlume 83-A - NUmber 5 - MAY 2001
IMPACT OF SMOKING ON THE OUTCOME OF ANTERIOR CERVICAL ARTHRODESIS WITH INTERBODY OR STRUT-GRAFTING

\section{Results}

successful fusion was achieved at all grafted sites in 144 of A the 190 patients included in this study; thus the overall rate of fusion was $76 \%$. The rate of solid osseous union was significantly higher among nonsmokers (110 of 135 patients, or $81 \%$ ) than among smokers (thirty-four of fifty-five patients, or $62 \%)(\mathrm{p}<0.02)$. This difference was also significant among patients who had undergone a multilevel discectomy and interbody fusion: all fusion levels healed in sixty-nine (76\%) of ninety-one nonsmokers compared with only twenty $(50 \%)$ of forty smokers $(\mathrm{p}<0.02)$ (Figs. $1-\mathrm{A}$ and $1-\mathrm{B})$. In comparison, with the numbers available there was no significant difference in the union rates between nonsmokers and smokers who had undergone corpectomy and strut-grafting: solid fusion was achieved at two years in forty-one (93\%) of forty-four nonsmokers and in fourteen (93\%) of fifteen smokers (Table I).

Clinical success was closely associated with the success of the arthrodesis. The nonsmokers had fifty-eight excellent results, sixty-two good results, thirteen fair results, and two poor results. The smokers had fifteen excellent results, twentyseven good results, twelve fair results, and one poor result. On the basis of rank-sum analysis, the clinical outcomes among the nonsmokers were significantly better than those among the smokers $(p<0.03)$. In the group in which multilevel interbody grafting had been performed, the outcomes among the nonsmokers were also significantly better than those among the smokers $(\mathrm{p}<0.02)$. However, in the group treated with subtotal corpectomy and strut-grafting, there was no significant difference between the clinical outcomes of the nonsmokers and smokers $(\mathrm{p}=0.67)$ (Table II).

We also compared the clinical outcomes in the patients in whom a pseudarthrosis developed with the outcomes in the patients who had a solid fusion (Table III). Of the forty-eight patients with a nonunion, five had an excellent clinical outcome; twenty-six, a good outcome; fourteen, a fair outcome; and three, a poor outcome. In comparison, the 142 patients with a solid union had sixty-eight excellent, sixty-three good, eleven fair, and no poor clinical outcomes. According to the rank-sum analysis, the outcomes were significantly better for patients who had a solid fusion $(\mathrm{p}<0.0001)$.

\section{Discussion}

A chieving anterior cervical interbody fusion at multiple Alevels is more challenging than is achieving such fusion at a single level ${ }^{15,20-23}$. We hypothesized that, if smoking had a negative effect on the healing of anterior cervical interbody grafts, it would be most pronounced when the grafts were used at multiple levels. By excluding patients who had undergone one-level interbody grafting from the present analysis, we did demonstrate a negative impact of smoking on the healing of multilevel anterior cervical interbody grafts. This finding conflicts with the reports of An et al. ${ }^{16}$ and Bohlman et al. ${ }^{15}$. However, in those studies approximately half of the patients underwent a single-level interbody grafting procedure, which may have masked the effects of smoking, since singlelevel grafts have been shown to have a very high rate of healing ${ }^{24-26}$. To our knowledge, only Bishop et al. ${ }^{14}$ demonstrated that cigarette-smoking affects the healing of interbody grafts in the cervical spine. In their study of 132 patients, they found a significantly lower rate of fusion $(p=0.004)$ among smokers who had received allograft but not among those who had received autograft. This is not surprising since it is more difficult to achieve fusion with allograft bone than with autograft bone.

Although others ${ }^{14-16}$ have attempted to demonstrate the impact of smoking on the healing of cervical interbody grafts, the effect of smoking on the healing of cervical strut grafts has never been reported, to our knowledge. In contrast to our findings with interbody grafts, we found that smoking had no impact on the healing of autogenous iliac and fibular strut grafts placed following subtotal cervical corpectomy at one or

TABLE II Functional Status of Nonsmokers and Smokers

\begin{tabular}{|c|c|c|c|c|}
\hline & Excellent & Good & Fair & Poor \\
\hline \multicolumn{5}{|l|}{ All procedures } \\
\hline Nonsmokers & 58 & 62 & 13 & 2 \\
\hline \multirow[t]{2}{*}{ Smokers } & 15 & 27 & 12 & 1 \\
\hline & & & & $p<0.03 *$ \\
\hline \multicolumn{5}{|c|}{ Multilevel discectomy and interbody grafting } \\
\hline Nonsmokers & 40 & 41 & 9 & 1 \\
\hline \multirow[t]{2}{*}{ Smokers } & 10 & 19 & 10 & 1 \\
\hline & & & & $\mathrm{p}<0.02 *$ \\
\hline \multicolumn{5}{|c|}{ Subtotal corpectomy and strut-grafting } \\
\hline Nonsmokers & 18 & 21 & 4 & 1 \\
\hline \multirow[t]{2}{*}{ Smokers } & 5 & 8 & 2 & 0 \\
\hline & & & & $p=0.67$ \\
\hline
\end{tabular}

*The $\mathrm{p}$ values represent the difference between the nonsmokers and the smokers. 
The Journal of Bone \& JOINT SURGERY $\cdot$ JBJS.ORG VOlume 83-A - NUmber 5 - MAY 2001
IMPACT OF SMOKING ON THE OUTCOME OF ANTERIOR CERVICAL Arthrodesis With INTERbody or Strut-Grafting

\begin{tabular}{lcccc}
\multicolumn{2}{l}{ TABLE III Functional Status Based on Outcome of } \\
Arthrodesis
\end{tabular}

more levels. In smokers and nonsmokers, the rate of fusion was $>90 \%$ (fifty-five of fifty-nine patients), which is close to the healing rates reported for single-level interbody grafts ${ }^{24,26}$. It should be noted that the healing of a strut graft is similar to the healing of a single-level interbody graft in that both require healing across only two osseous surfaces. However, in subtotal corpectomy with strut-grafting there may also be bone contact laterally, which facilitates fusion.

The present study also demonstrated significantly poorer clinical outcomes among smokers when compared with nonsmokers. With clinical success defined as a good or excellent result, 120 of the 135 nonsmokers in this study had a successful result compared with only forty-two of the fifty-five patients who had a history of cigarette-smoking ( $\mathrm{p}<0.03$, rank-sum analysis). It has been shown that the prevalence of symptomatic cervical disc disease is substantially higher among smokers than it is among nonsmokers ${ }^{27}$ and that cigarette-smoking has a systemic effect leading to intervertebral disc degeneration in the lumbar spine ${ }^{28}$. Furthermore, several studies have demonstrated a higher prevalence of wound infections among smokers who underwent posterior lumbar spine procedures ${ }^{5,9-11}$. However, the better outcomes among nonsmokers in our study may have been a function of their higher rate of fusion, since we found a very strong association between the development of a pseudarthrosis and a poorer clinical outcome among all of the patients in the study $(\mathrm{p}<0.0001)$.

This study confirms the prevailing theory that cigarette- smoking creates a biologically challenging environment in which anterior cervical interbody arthrodesis is less likely to be successful. We believe that the negative impact of smoking on graft-healing is additive with other factors, such as multilevel interbody grafting, the use of allograft bone, and interbody grafting adjacent to a solid fusion ${ }^{14-16,24,26,29,30}$. Since the poorer clinical outcomes among smokers were associated with their lower rate of fusion, we believe that strategies to improve the rate of fusion among smokers will also improve the clinical outcome. We strongly advise our patients to stop smoking prior to undergoing multilevel anterior cervical decompression. For patients who fail to do so, we recommend reconstruction with autogenous strut grafts rather than with interbody grafts. Although application of an anterior cervical plate may improve the rate of fusion with multiple interbody grafts ${ }^{25}$, the long-term impact of an anterior plate (compared with a strut graft) on clinical outcome remains unknown.

Alan S. Hilibrand, MD

The Rothman Institute, 925 Chestnut Street, 5th Floor, Philadelphia, PA 19107. E-mail address: alan.hilibrand@mail.tju.edu

Mark A. Fye, MD

Sanford E. Emery, MD

Henry H. Bohlman, MD

University Hospitals Spine Institute, 11100 Euclid Avenue, Cleveland, OH 44106

Mark A. Palumbo, MD

University Orthopaedics, Incorporated, 2 Dudley Street, Suite 200, Providence, RI 02905

No benefits in any form have been received or will be received from a commercial party related directly or indirectly to the subject of this article. No funds were received in support of this study.

\section{References}

1. Barendregt JJ, Bonneux L, van der Maas PJ. The health care costs of smoking. N Engl J Med. 1997;337:1052-7.

2. Kessler DA, Witt AM, Barnett PS, Zeller MR, Natanblut SL, Wilkenfeld JP, Lorraine CC, Thompson L, Schultz WB. The Food and Drug Administration's regulation of tobacco products. N Engl J Med. 1996;335:988-94.

3. Lucas TS, Einhorn TA. Osteoporosis: the role of the orthopaedist. J Am Acad Orthop Surg. 1993;1:48-56.

4. Brown CW, Orme TJ, Richardson HD. The rate of pseudarthrosis (surgical nonunion) in patients who are smokers and patients who are nonsmokers: a comparison study. Spine. 1986;11:942-3.

5. Capen DA, Calderone RR, Green A. Perioperative risk factors for wound infections after lower back fusions. Orthop Clin North Am. 1996;27:83-6.

6. Carpenter CT, Dietz JW, Leung KY, Hanscom DA, Wagner TA. Repair of a pseudarthrosis of the lumbar spine. A functional outcome study. J Bone Joint Surg Am. 1996;78:712-20.

7. Hadley MN, Reddy SV. Smoking and the human vertebral column: a review of the impact of cigarette use on vertebral bone metabolism and spinal fusion. Neurosurgery. 1997;41:116-24.

8. Hanley EN, Levy JA. Surgical treatment of isthmic lumbosacral spondylolisthesis. Analysis of variables influencing results. Spine. 1989;14:48-50.
9. Lehto MU, Honkanen P. Factors influencing the outcome of operative treatment for lumbar spinal stenosis. Acta Neurochir (Wien). 1995;137:25-8.

10. Thalgott JS, Cotler HB, Sasso RC, LaRocca H, Gardner V. Postoperative infections in spinal implants. Classification and analysis - a multicenter study. Spine. 1991;16:981-4.

11. Wimmer C, Gluch H, Franzreb M, Ogon M. Predisposing factors for infection in spine surgery: a survey of 850 spinal procedures. J Spinal Disord. 1998;11:124-8.

12. Daftari TK, Whitesides TE, Heller JG, Goodrich AC, McCarey BE, Hutton WC. Nicotine on the revascularization of bone graft. An experimental study in rabbits. Spine. 1994;19:904-11.

13. Silcox DH, Daftari T, Boden SD, Schimandle JH, Hutton WC, Whitesides TE. The effect of nicotine on spinal fusion. Spine. 1995;20:1549-53.

14. Bishop RC, Moore KA, Hadley MN. Anterior cervical interbody fusion using autogeneic and allogeneic bone graft substrate: a prospective comparative analysis. J Neurosurg. 1996;85:206-10.

15. BohIman HH, Emery SE, Goodfellow DB, Jones PK. Robinson anterior cervical discectomy and arthrodesis for cervical radiculopathy. Long-term follow-up of one hundred and twenty-two patients. J Bone Joint Surg Am. 1993;75:1298-307.

16. An HS, Simpson JM, Glover JM, Stephany J. Comparison between allograft 
The JOURNAL OF BONE \& JOINT SURGERY $\cdot$ JBJS.ORG VOLUME 83-A · NUMBER 5 - MAY 2001
IMPACT OF SMOKING ON THE OUtCOME OF ANTERIOR CERVICAL ARTHRODESIS WITH INTERBODY OR STRUT-GRAFTING

tients. J Bone Joint Surg Am. 1973;55:525-34

plus demineralized bone matrix versus autograft in anterior cervical fusion. A prospective multicenter study. Spine. 1995;20:2211-6.

17. Robinson RA, Smith GW. Anterolateral cervical disc removal and interbody fusion for cervical disc syndrome. Bull Johns Hopkins Hosp. 1955;96:223-4.

18. Emery SE, BohIman HH, Bolesta MJ, Jones PK. Anterior cervical decompression and arthrodesis for the treatment of cervical spondylotic myelopathy. Two to seventeen-year follow-up. J Bone Joint Surg Am. 1998;80:941-51.

19. Robinson RA, Walker AE, Ferlic DC, Wiecking DK. The results of anterior interbody fusion of the cervical spine. J Bone Joint Surg Am. 1962;44:1569-87.

20. DePalma AF, Rothman RH, Lewinnek GE, Canale ST. Anterior interbody fusion for severe cervical disc degeneration. Surg Gynecol Obstet. 1972;134:755-8.

21. Emery SE, Fisher JR, BohIman HH. Three-level anterior cervical discectomy and fusion: radiographic and clinical results. Spine. 1997;22:2622-5.

22. Riley LH, Robinson RA, Johnson KA, Walker AE. The results of anterior interbody fusion of the cervical spine. Review of ninety-three consecutive cases. J Neurosurg. 1969;30:127-33.

23. White AA, Southwick WO, Deponte RJ, Gainor JW, Hardy R. Relief of pain by anterior cervical-spine fusion for spondylosis. A report of sixty-five pa-
24. Brodke DS, Zdeblick TA. Modified Smith-Robinson procedure for anterior

25. Connolly PJ, Esses SI, Kostuik JP. Anterior cervical fusion: outcome analysis of patients fused with and without anterior cervical plates. J Spinal Disord. 1996;9:202-6.

26. Emery SE, Bolesta MJ, Banks MA, Jones PK. Robinson anterior cervical fusion. Comparison of the standard and modified techniques. Spine. 1994;19:660-3.

27. An HS, Silveri CP, Simpson JM, File P, Simmons C, Simeone FA, Balderston RA. Comparison of smoking habits between patients with surgically confirmed herniated lumbar and cervical disc disease and controls. J Spinal Disord. 1994;7:369-73.

28. Battie MC, Videman T, Gill K, Moneta GB, Nyman R, Kaprio J, Koskenvuo M. Smoking and lumbar intervertebral disc degeneration: an MRI study of identical twins. Spine. 1991;16:1015-21.

29. Hilibrand AS, Yoo JU, Carlson GD, Bohlman HH. The success of anterior cervical arthrodesis adjacent to a previous fusion. Spine. 1997;22:1574-9.

30. Zdeblick TA, Ducker TB. The use of freeze-dried allograft bone for anterior cervical fusions. Spine. 1991;16:726-9. cervical discectomy and fusion. Spine. 1992;17(10 Suppl):S427-30. 